\title{
PABLO GARGALLO Y EL NACIMIENTO DE LA MODERNIDAD. LITERATURA, FOTOGRAFÍA Y CINE
}

Análisis de la relación estética de la obra escultórica de Pablo Gargallo con la literatura cubista, la fotografía y el cine. La teoría poética de Pierre Reverdy, la resolución en luces y sombras de la fotografía, y el montaje y primeros planos cinematográficos constituyen un referente clave a la hora de entender la obra del escultor.

Palabras clave: Pablo Gargallo; Literatura; Fotografía; Cine.

The author presents an analysis of the aesthetic relationship between the sculptural works of Pablo Gargallo and Cubist literature, photography and cinema. Pierre Reverdy's poetic theory, the solutions of light and shadow found in photography, film editing and film close-ups are all key references for understanding the work of this sculptor. Key words: Pablo Gargallo; Literature; Photography; Cinema.

Este trabajo es el resultado de una investigación llevada a cabo sobre tres aspectos poco estudiados en torno a la obra del escultor Pablo Gargallo, y que reflejan el papel decisivo que desempeñó como artista en los movimientos estéticos de la primera vanguardia. Por otra parte, reflexionamos sobre la relación de la obra escultórica de Gargallo con tres lenguajes con los que 
mantuvo un diálogo creativo permanente y en donde queda manifiesta tanto la influencia como el intercambio de ideas entre el artista y el mundo de la literatura, la fotografía y el cine.

La amistad de Pablo Gargallo con el poeta francés Pierre Reverdy explica en gran medida la presencia del cubismo, uno de los caminos abiertos en su trayectoria. Pierre Reverdy, considerado uno de los máximos exponentes de lo que se conoce como poesía cubista, aunque él mismo rechazara este término, fue además un relevante teórico del cubismo en los primeros años de gestación. Las conversaciones entre ambos, sus contactos personales con los protagonistas del incipiente movimiento vanguardista, tanto pictórico como literario, los sitúan en un lugar y en un momento privilegiado al que no es ajena la evolución que seguirán las esculturas de Pablo Gargallo, siendo manifiesta la confluencia de recursos expresivos entre el lenguaje del espacio propuesto por Gargallo y la poética del espacio puesta en práctica por su amigo Pierre Reverdy.

En cuando a la fotografía, el escultor utilizó de manera sistemática la fotografía, no sólo para documentar su obra, sino como utensilio de trabajo que le permitía interpretar posibilidades diversas a partir de una misma idea, tal y como se deduce al estudiar con detalle las imágenes que se conservan en el archivo personal del artista.

Lo mismo podemos decir acerca del cine, hacia el que Gargallo nunca se mostró indiferente sino todo lo contrario, como lo prueban las obras que el escultor dedicó a algunas estrellas de Hollywood que en aquellos años gozaban de extrema popularidad. Sorprende cotejar las imágenes más populares de Greta Garbo con la interpretación que Pablo Gargallo hizo de la actriz. Por otro lado, la vinculación de Pablo Gargallo con el cine no es sólo de tipo argumental, sino que obedece a unos planteamiento formales mucho más profundos en donde se puede establecer un paralelismo formal entre los procedimientos expresivos introducidos por el cine, como el montaje de planos, y la construcción de esculturas a partir de superficies planas, recortadas y montadas posteriormente hasta reproducir la sensación de espacio y simultaneidad espacial, tal y como sucede en el terreno de lo visual. Existe, pues, una correspondencia formal entre los cartones que Pablo Gargallo utiliza como etapa previa de diseño para sus trabajos en chapa y proceso de montaje cinematográfico a partir de segmentos de espacio y tiempo que, una vez ensamblados los unos y los otros, dan como resultado un discurso basado en la elipsis, es decir, en el espacio vacío, como signo de identidad. Esa elipsis o espacio vacío sólo podrá ser completada mediante la participación activa del espectador, otro de los rasgos formales que determinan la modernidad del arte y de la obra de Gargallo desde principios de siglo XX. Tampoco hay que pasar por alto la vinculación que tuvo su hermano Francisco con el cine, realizador de populares filmes en esos mismos años en Barcelona, tal y como se muestra a continuación.

Para llevar a cabo nuestra investigación, hemos contado con la ayuda inestimable de la hija del escultor, Pierrette Gargallo, que nos ha permitido acceder al fondo documental de imágenes que conserva en París sobre el trabajo de su padre y que se estudian aquí por primera vez desde un punto de vista estético, y del experto Rafael Ordóñez Fernández, autor de los catálogos razonados del museo Pablo Gargallo de Zaragoza y comisario de diversas exposiciones dedicadas al escultor. Del mismo modo, hemos consultado los fondos cinematográficos de las filmotecas nacional y de Cataluña rastreando la huella y el legado de Francisco Gargallo como realizador y su eventual vinculación con el universo escultórico de su hermano Pablo.

Pablo Gargallo llega a París por primera vez en 1903. Los llamados escritores decadentes reaccionan en contra de la estética naturalista dominante, que tiene la descripción precisa y detallada de la realidad como uno de sus pilares fundamentales. Un escritor como Huysmans, que comienza su trayectoria como escritor adscrito a los dictados de Zola, rompe definitivamente en 1884 con su novela $A$ Rebours denunciando en el prólogo los excesos de la estética naturalista. Buñuel escribirá años más tarde un guión basado en otra novela de Huysmans, Là bas, que nunca llegará a materializarse en película. Baudelaire ha firmado su conocida diatriba contra la fotografía, uno de los textos más citados en teoría de la imagen y peor entendidos. La misiva del autor de Las flores del mal estaba dirigida contra una estética que reducía la obra de arte a una 
reproducción realista [Zola en La novela experimental (1880) compara las técnicas miméticas de la escritura con la fotografía]. Jules Renard publica Histories naturelles en 1894 y Mallarmé su relevante Un coup de dés jamais n'abolira le hasard en 1897. Schwob muere en 1905 y Remy de Gourmont en 1915. Son escritores que ofrecen una forma distinta de ver y contar el mundo que, objeto de un adecuado proceso de manufacturado intelectual, se consolidará en las llamadas vanguardias históricas.

Gargallo, como escultor, participa directamente, por formación y convicciones personales, en esta tradición decimonónica, que siempre reivindicará como la base fundamental sobre la que se desarrolla el conjunto de su trabajo. En los años del cambio de siglo se fraguan los conceptos estéticos y los procedimientos creativos que, por un exceso de veneración a postulados supuestamente modernos, se atribuye a las vanguardias, y en particular al surrealismo. El mundo de los sueños y lo sobrenatural como fuente de conocimiento, característico del surrealismo, tiene su origen en las propuestas de escritores de finales de siglo.

$\mathrm{Su}$ trabajo y sus opiniones muestran tanto el respeto a la tradición decimonónica como su convicción más firme en las innovaciones vanguardistas. "Apostar por un esfuerzo en la renovación de los medios plásticos -leemos en una de sus notas- no significa en absoluto desprecio de la tradición y de lo que cada época ha contribuido. Siempre he trabajado y trabajo todavía con los medios del pasado, asimilados a mi manera. No he abandonado la tradición. Valoro lo que hago en relación a mis contemporáneos, y el respeto que siento hacia mis mayores es tan grande que temo que nos consideren profanadores al vernos enfrascados como estamos en sus procedimientos" ". El caso de un fotógrafo como Alvin Langdon Coburn ilustra bien las circustancias de otros muchos artistas que viven, como Gargallo, el cambio de siglo. Coburn se encuentra en la capital francesa visitando y fotografiando en 1913 a conocidos suyos como Gertrude Stein o Matisse. Adscrito a la estética pictorialista del XIX, decide vincularse al vorticismo de Wyndham Lewis y Ezra Pound, que el mismo Coburn describe en su Autobiografia ${ }^{2}$ como tardofuturismo y tardocubismo, consciente de subirse al tren de la historia realizando en 1916 diversas vortografías, entre las que se encuentra el conocido retrato de poeta de los Cantos de acuerdo con una descomposición caleidoscópica mediante cristales de las formas de representación tradicionales. No resulta descabellado trazar un paralelismo formal entre la evolución estética de Coburn y la apertura formal de Gargallo hacia los planteamientos que irrumpen desde el cubismo pictórico. Se trata de una misma evolución desde el clasicismo decimonónico a la descomposición y composición de la realidad en múltiples planos montados que superpuestos ofrecen una impresión de simultaneidad.

Cuando Gargallo vuelve a la capital francesa en el otoño de 1912, poco antes del estallido de la primera guerra mundial, es la época de Max Jacob y Pierre Reverdy, el reencuentro con Picasso, la amistad con Juan Gris, quien le presentará a su futura mujer Magali. El cubismo ha alcanzado su madurez, pasando del periodo analítico a lo que se ha denominado su etapa sintéti$\mathrm{ca}^{3}$. A propósito del concepto de cubismo sintético explicaba Juan Gris, en una conferencia pronunciada en la Sorbona poco antes de su muerte, que "el análisis estético tendría como función disociar el mundo exterior para extraer los elementos de una misma categoría. La técnica podría entonces asociar esos elementos formales hasta alcanzar una unidad, que sería sintética" ${ }^{\text {. En }}$ 1913 Blaise Cendrars publica uno de los más importantes textos de la época, el poema La prose

\footnotetext{
1 Gargallo, Paris, éditions Carmen Martínez, 1979, p. 41.

2 CoBurn, Alvin Langdon: Photographer. An Autobiography (edited by Helmut and Alison Gernsheim), New York, Dover Publications, 1978.

3 Ver COOPER, Douglas: La época cubista, Madrid, Alianza, 1984.

${ }^{4}$ Gris, Juan: Des possibilités de la peinture (1924), incluido en KahnweILER, Daniel-Henry: Juan Gris, sa vie, son æeuvre, ses écrits, Paris, Gallimard, 1946, p. 280.
} 
du Transsibérien et de la Petite Jeanne de France, un libro de dos metros de altura ilustrado por Delaunay. Un grupo importante de escritores y críticos, entre los que se encuentran André Salmon y Guillaume Apollinaire, del que en marzo aparece Les peintres cubistes, méditations esthétiques, además de Max Jacob, Pierre Reverdy y Maurice Raynal, amigos de Gargallo, defienden y colaboran en la difusión del movimiento y la estética cubista ${ }^{5}$. Se ha querido ver una particular influencia de las ideas y planteamientos del cubismo en esculturas como Maternidad o Mujer sentada, ambas de 1922, donde la representación de los volúmenes convencionales cóncavos es substituida por formas convexas, invirtiendo de ese modo el concepto tradicional de espacio. La hija del escultor, Pierrette Gargallo, recuerda las largas conversaciones entre su padre y el poeta Pierre Reverdy, que en esos momentos participa de manera activa en la articulación teórica de los planteamientos estéticos del cubismo.

El argumento fundamental que Baudelaire utiliza en contra de la fotografía y del naturalismo, en tanto que discurso aferrado a la descripción de la realidad, es que el artista no debe pintar lo que ve sino lo que piensa o lo que sueña ${ }^{6}$. Uno de los objetivos en los que coinciden artistas e intelectuales de la época es el propósito de desembarazarse de la realidad como un lastre que limitaba las posibilidades de expresión de la pintura y la poesía limitándola a modos descriptivos. "Conviene la abstracción -declara Gargallo a Masip, que lo entrevista durante su viaje a Barcelona en 1928 para firmar el contrato de cuatro obras monumentales con destino a la Exposición Internacional de Barcelona de 1929-. El realismo, en esencia, tiende a difuminar la personalidad, incluso colectiva, en el arte" . Gargallo, fiel a la tradición escultórica, expresa aquí su rechazo del realismo en favor de una concepción pura del arte, abstracta, dice Gargallo, esencial, puntualizaría su amigo Reverdy, un adjetivo compartido y muy utilizado en sus reflexiones, para distinguir su búsqueda del mero propósito mimético, realista. Al mismo tiempo, señala su empeño y determinación en desarrollar nuevos caminos, el de la construcción de su primera máscara con chapa, mirando al futuro y en sintonía con su tiempo, que coinciden con la época cubista. No obstante, expresa al mismo tiempo su rechazo hacia un vanguardismo gratuito, desacreditado, y las críticas abiertas del surrealismo que califica de excesivamente literario, fragmentado e incompleto.

En este sentido, Pierre Reverdy, en un artículo titulado "Le cubisme poésie plastique", escribía: "Despejar, para crear, los vínculos que las cosas tienen entre sí, para acercarlas. Esa ha sido siempre la finalidad de la poesía. Los pintores han aplicado este procedimiento a los objetos y, en lugar de representarlos, han utilizado esos vínculos que descubrían. Como consecuencia tiene lugar una reconstrucción en lugar de una interpretación. Se trata de un arte de concepción"8. La trayectoria escultórica de Gargallo se desprende de elementos formales convencionales, apuesta por un progresivo alejamiento de la representación naturalista de la realidad en búsqueda de fórmulas nuevas, tanto en materiales como en procedimientos expresivos, substituyendo la representación realista del volumen por una construcción del espacio intelectual, es decir, en donde el espectador debe intervenir en la creación de la propia escultura imaginando y completando las figuras sugeridas, tal y como queda reflejado, por las mismas razones estéticas, en este autorretrato de Pierre Reverdy:

\footnotetext{
5 Consultar Europe, 638-639, “Cubisme et littérature”, junio-julio 1982.

${ }^{6}$ Baudelaire, Charles: carta del poeta al director de la Revue Française (Salon de 1859), incluido en Du bon usage de la photographie (Michel Frizot, Françoise Ducros, eds.), Paris, Centre Nationale de la Photographie, 1987, pp. 27-34.

7 MASIP, Josep Maria: “L'escultor Pau Gargallo i l'art modern, converses de La Nau”, junio 1928.

${ }^{8}$ Reverdy, Pierre: "Le cubisme, poésie plastique", L'art, febrero 1919, incluido en Nord-Sud, Self Defence et autres écrits sur l'art et la poésie (1917-1926), Paris, Flammarion, 1975, pp. 142-143.
} 


\author{
YO MISMO \\ Un nicho \\ Un número \\ Un grupo de hombres \\ Todo el final está allí \\ Ya no se avanza \\ Un astro reluce \\ Doce menos cuarto \\ La puerta es demasiado grande \\ Los árboles ronronean \\ Y el cielo más abajo \\ Es para la despedida \\ Estoy en el umbral \\ La luna mengua \\ Una lágrima aparte ${ }^{9}$
}

En 1868, Lautréamont formula en su célebre Chants de Maldoror uno de los conceptos clave que sientan los pilares del arte moderno: la belleza como "el encuentro fortuito entre una máquina de coser y un paraguas sobre una mesa de operaciones", definición que Man Ray pondrá en escena en su famosa fotografía de 1933. La gran innovación en la propuesta de Lautréamont, que va a generalizarse constituyendo uno de los fundamentos de la poética moderna, es que la imagen renuncia al vínculo construyendo su significado sobre la descarga que de ese encuentro, deliberado o fortuito, entre dos elementos dispares tiene lugar. No hay otra justificación para ese encuentro que la estricta sorpresa y la emoción estética que de ello se deriva. La noción de Lautréamont se repite en el Arte poético de Max Jacob en $1915^{10}$, y de forma explícita en la definición de imagen poética que Pierre Reverdy publicó en su revista Nord-Sud en 1918:

"La imagen es pura creación del entendimiento.

No puede nacer de una comparación sino de la aproximación de dos realidades más o menos alejadas.

Cuanto más alejada y certera sea la relación entre las dos realidades reunidas, más intensa será la imagen, más fuerza emotiva y realidad poética tendrá" ${ }^{11}$.

Planteamiento que vuelve a repetirse en los mismos términos, con el elemento de azar añadido, en el manifiesto surrealista de 1924 firmado por Breton y en la definición que Max Ernst propone del collage ${ }^{12}$ o la técnica del montaje de choque para el cine expuesta por Eisenstein en 1923 en "El montaje de atracción"13. Nos encontramos ante uno de los aspectos clave en la articulación del lenguaje del arte a partir de finales del siglo XIX, la asociación de elementos heterogéneos sin un vínculo necesario que hace saltar la emoción de la poesía en su más amplio sentido de la palabra.

\footnotetext{
9 Reverdy, Pierre: "Moi-même" en La guitarre endromie (1919), incluido en La plupart du temps 1915-1922, Gallimard, Paris, 1945 (vol. II), p. 49.

10 JACOB, Max: Art poétique, Paris, L’Eloquent, 1987.

11 Reverdy, Pierre: "L'image", Nord-Sud, 13, marzo 1918, incluido en Nord-Sud, Self Defence, op. cit., p. 73.

12 Un clásico sobre la historia del collage, aunque con cierta falta de perspectiva histórica, es el libro de ARAGON, Louis, Les collages, Paris, Hermann, 1965.

${ }^{13}$ EisensteIn, Sergei: "Montage of Attractions" incluido en The Film Sense, London, Faber \& Faber, 1986, pp. 181-183.
}

Arch. esp. arte, LXXXIV, 333, ENERO-MARZO 2011, 59-90, ISSN: 0004-0428 
La participación del espectador es uno de los aspectos claves en el arte moderno. La obra no está completa (literaria, escultórica o cinematográficamente hablando) sin la intervención activa del receptor. La plasmación del vacío en los poemas de Reverdy y en las esculturas de Gargallo es un síntoma, más que la forma propiamente dicha, del hallazgo trascendental del arte en donde la existencia del espacio literario y escultórico resulta imposible sin la intervención activa de la mirada. Gargallo participa de una corriente que remonta a Lautréamont y se materializa verbalmente en la definición de imagen formulada por su amigo Reverdy en 1917, y que va mucho más allá del concepto estrictamente iconográfico.

La idea de imagen, en términos expresivos, es compartida por la literatura, la pintura para teóricos y artistas cubistas, el collage tal y como Max Ernst y Aragon lo definían en los años 30, las fotografías de Coburn o Man Ray, la definición que del montaje de choque hace Eisenstein en términos cinematográficos, o el principio intelectual y expresivo que fundamenta las esculturas "montadas" de Gargallo a partir de plantillas. El vacío en sus esculturas es, por tanto, un síntoma, y la mirada cómplice su consecuencia más importante.

Un segundo aspecto a tener en cuenta es el uso que Gargallo hizo de la fotografía como algo más que una mera herramienta en la concepción y desarrollo de su trabajo escultórico. Gargallo fotografía sistemáticamente sus esculturas. No sólo como trabajo documental de las obras que va elaborando, sino que realiza imágenes de su trabajo en curso de manera que la fotografía permitía, a lo largo del desarrollo de una misma obra, reflexionar sobre la evolución de la misma y tomar decisiones que cambiaban el curso y su resolución final. Una vez concluida la obra, Gargallo desestimaba esas imágenes a modo de bocetos, apuntes, notas que se transformaban hasta alcanzar el aspecto definitivo que hoy conocemos. Al estudiar de cerca la máscara titulada El drama, realizada y fotografiada por Gargallo hacia 1915, dada por perdida, y compararla con la titulada La tragedia, de la misma época, descubrimos las sorprendentes similitudes que nos hacen pensar en una misma escultura objeto de diversas modificaciones. El drama y La tragedia pudiera tratarse de una única obra, o si se prefiera de dos versiones de un mismo proyecto, al que Gargallo ha cambiado el pelo y la boca, añadido un pendiente, conservando la estructura completa del rostro (figs. 1 y 2). Variantes y detalles que cambian se muestran al cotejar las fotografías de Gargallo de Torso de mujer, de 1915, con el aspecto definitivo de la obra, a la que el escultor ha añadido la espalda y cerrado las piernas (figs. 3 y 4). Otro tanto sucede con los diferentes estadios y partes del retrato de Angel Fernández de Soto documentados fotográficamente por el escultor a lo largo de 1920 (figs. 5, 6, 7, y 8), así como en Homenaje a Marc Chagall, de 1933, donde verificamos, gracias a las imágenes de Gargallo, cómo alarga el pie para otorgar mayor esbeltez al retrato (figs. 9 y 10). Para la realización de las tomas se servía de una cámara de placas de $18 \times 24$, más técnica y compleja, y sin duda menos manejable, que cualquiera de las cámaras compactas a su alcance. Además de usar la fotografía con una finalidad técnica y documental, gustaba retratar a los amigos que pasaban por el estudio, como el músico José Soler Casabón, oriundo de la anegada Mequinenza, el crítico Maurice Raynal o el poeta Pierre Reverdy (fig. 11).

Observamos en sus reflexiones la forma en que Gargallo entiende la escultura y la similitud con la dimensión lumínica de la fotografía propiamente dicha, como si el escultor llevara a cabo una interpretación fotográfica de la naturaleza escultórica. "La escultura es un problema de luz y de sombra" ${ }^{14}$, apunta en una de sus notas. La fotografía en blanco y negro también. Esta observación y otras similares revelan la preocupación de Gargallo por la tridimensionalidad de la escultura, y se propone superar las limitaciones de la percepción del volumen escultórico mediante la supresión de la materia dejando que la luz desempeña un papel clave en la percepción de la

14 Gargallo, Paris, éditions Carmen Martínez, 1979, p. 89. 


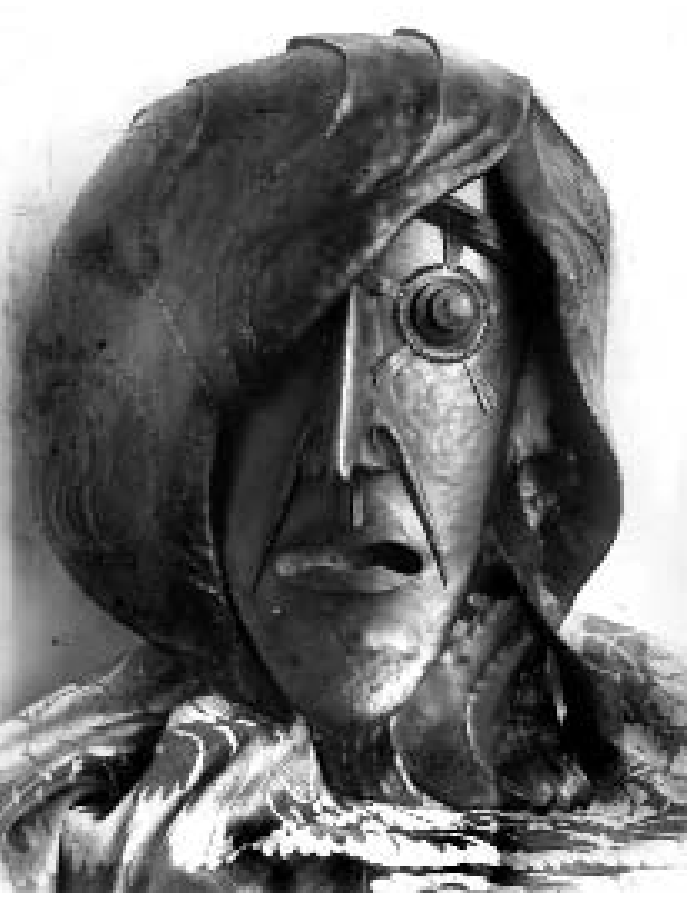

Fig. 1. El drama (c. 1915), foto Pablo Gargallo.

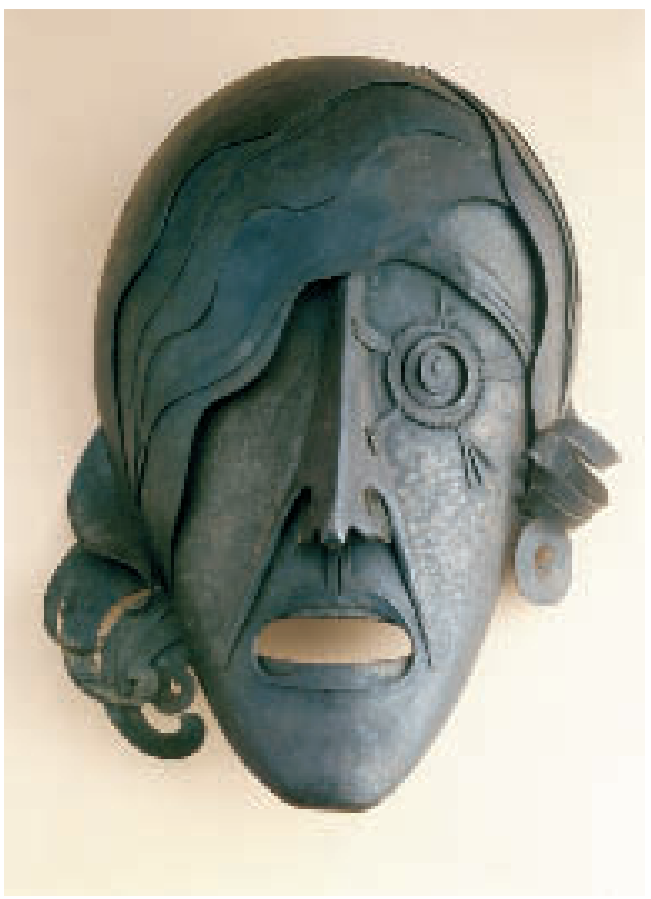

Fig. 2. La tragedia (c. 1915), foto Christie'es, 1991.

obra y su espacio, más intuido que físico. Para el escultor la iluminación de su trabajo tiene un valor que va mucho más allá del ornamental. La luz desempeña una función plástica, expresiva, tan importante como el objeto mismo, que subraya en claros y oscuros. En ocasiones dejó la tarea de fotografiar su trabajo a profesionales como Emmanuel Sougez, autor de algunas de las imágenes estudiadas. Sougez realizó un importante trabajo fotográfico antes de la gran guerra, y su profesionalidad y preocupación por la utilización de la luz en los trabajos de Sougez no tuvo que pasar inadvertida a Gargallo. La luz constituye un componente más en la obra escultórica de Pablo Gargallo, y así lo entendió con acierto el fotógrafo Jean Bescós a la hora de fotografiar sus esculturas en el magnífico trabajo de interpretación y edición que es el libro Gargallo publicado en 1979. La técnica de iluminación de Bescós es extraordinaria y con una capacidad de visión que sintoniza con el escultor y recrea toda la dimensión volumétrica y espacial de su obra.

A propósito de la iluminación de las diferentes superficies y volúmenes constatamos, a propósito de las esculturas de la época cubista donde Gargallo invierte los volúmenes cóncavos en convexos, que el escultor es muy consciente de las consecuencias que tiene la incidencia de la luz en el modo de percibir sus esculturas:

"El relieve convexo -anota- está constituido de construcciones de sombra y luz deslizantes, huidizas, con reflejos que deforman pues recibe siempre diversos rayos de luz. El cóncavo es franco y sin relieve, con extraordinarias finezas en el claro-oscuro y conserva, uniéndolos, todos los rayos de luz que recibe. La superficie plana resulta constructiva, uniforme e inmóvil. Esto es lo que la escultura debe a la arquitectura"15.

15 Ibid., p. 89. 


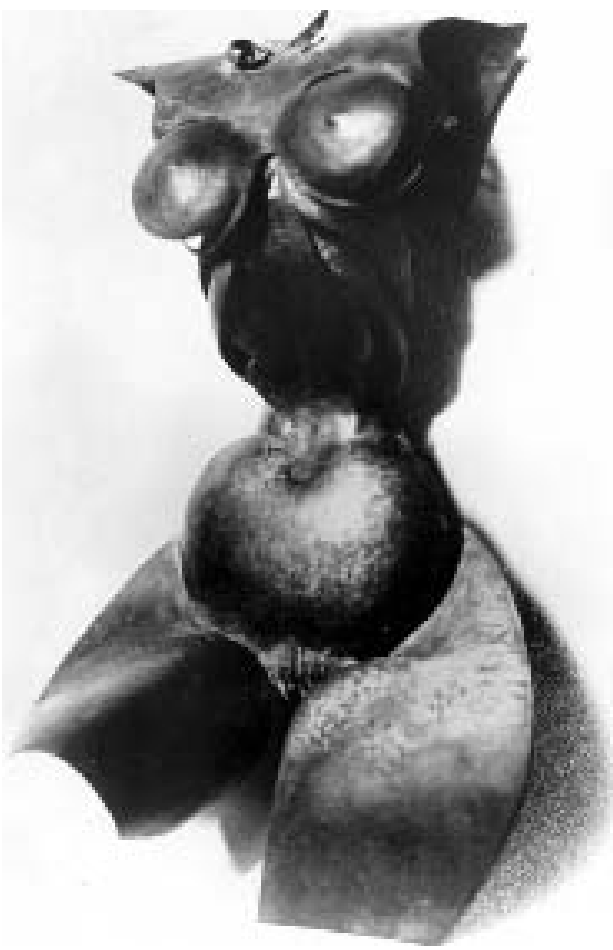

Fig. 3. Torso de mujer (1) (c. 1915), foto Pablo Gargallo.

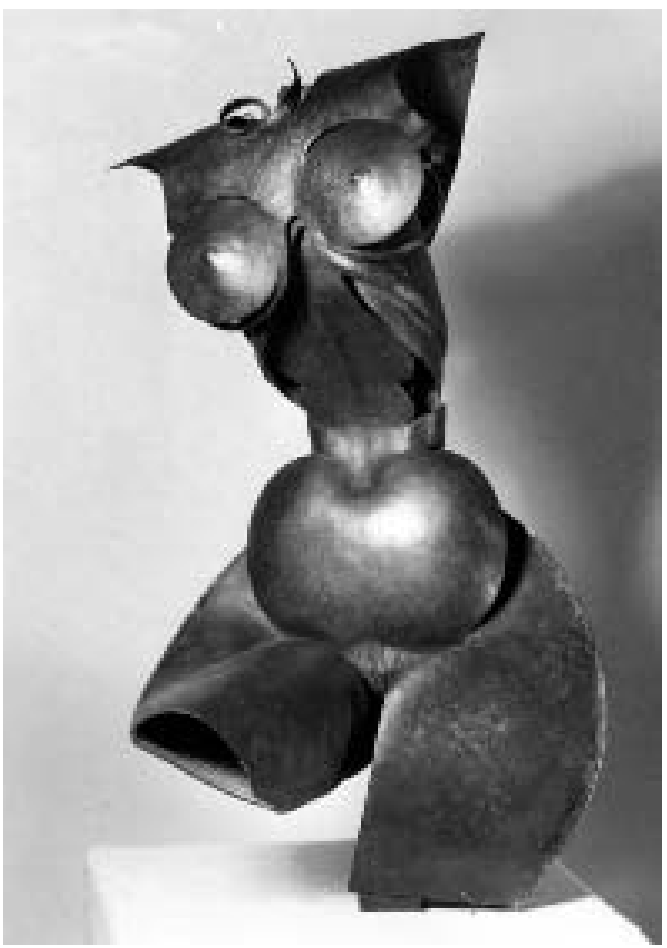

Fig. 4. Torso de mujer (2) (c. 1915), foto Emmanuel Sougez.

Gargallo, por otra parte, se expresa en términos que son comunes y familiares en el ámbito fotográfico y trata cuestiones ante las que un profesional se enfrenta ante cualquier objeto y en particular la fotografía de arquitectura -Bescós, además de ejercer como fotógrafo de la obra del escultor, es de profesión arquitecto- donde las cuestiones de luz y volumen resultan decisivas a la hora de alcanzar unos resultados óptimos. Sólo alguien particularmente familiarizado y sensible a los problemas que representa la luz, sus matices, sus posibilidades y consecuencias es capaz de hablar de este modo. En otros fragmentos de sus escritos reaparecen de nuevo, en este sentido, un vocabulario característico del cubismo como concepto, asociación y síntesis, directamente relacionado con cuestiones de emplazamiento o, dicho en términos fotográficos, encuadre e iluminación:

"La escultura sólo puede especular con el volumen. Debe ser concebida gracias a la ayuda de volúmenes sintéticos reales y complementarios, y en donde la materia está al servicio únicamente de una mejor realización y adaptación de su emplazamiento, de su iluminación y de su concepción"16.

En lo que respecta al séptimo arte, el cine despertó entre los artistas e intelectuales de la época un gran entusiasmo, como refleja "Cinématographe"17, que Pierre Reverdy publica en el número

16 Ibid., p. 149.

${ }_{17}$ Reverdy, Pierre: "Cinématographe", Nord-Sud, 16, 1918, incluido en Nord-Sud, Self Defence et autres écrits sur l'art et la poésie, op. cit., pp. 91-95. 


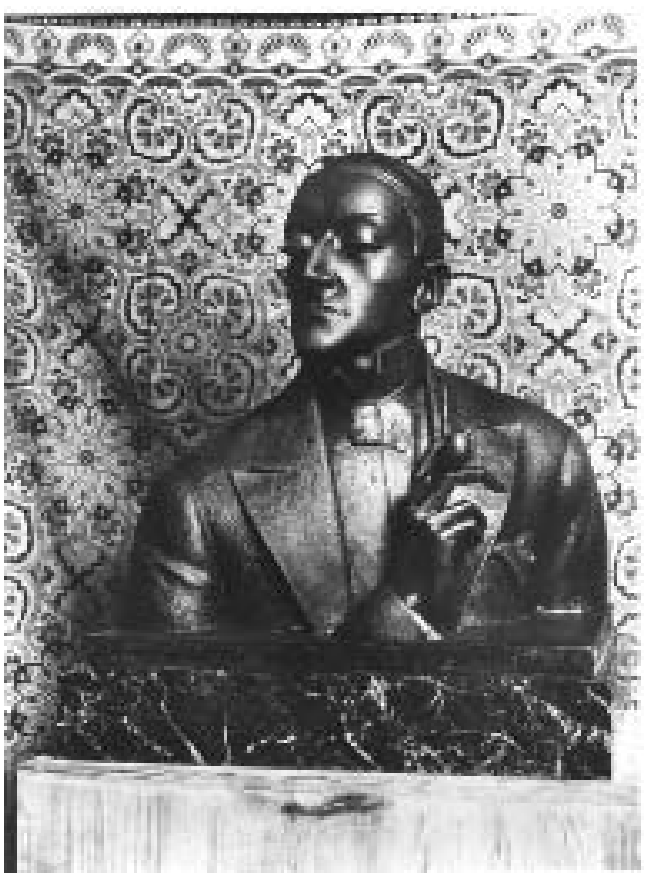

Fig. 5. Ángel Fernandez Soto (1) (1920), foto Pablo Gargallo.

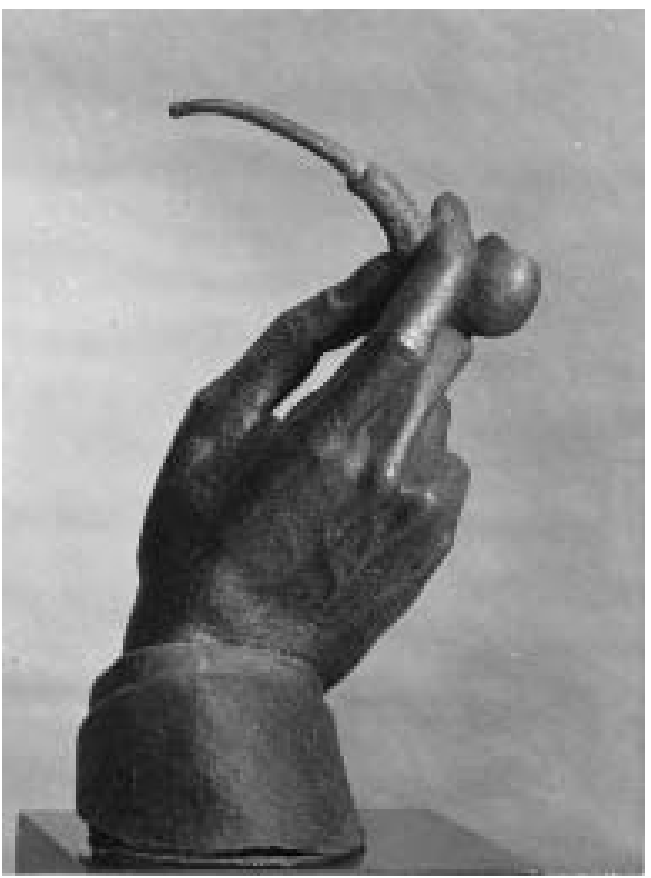

Fig. 7. Ángel Fernandez Soto (3) (1920), foto Pablo Gargallo.

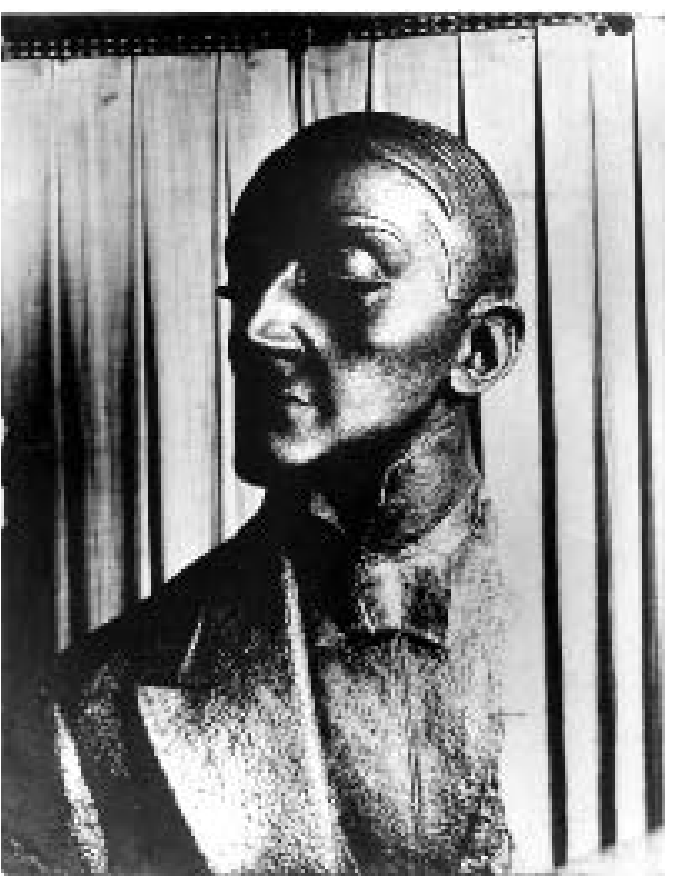

Fig. 6. Ángel Fernandez Soto (2) (1920), foto Pablo Gargallo.

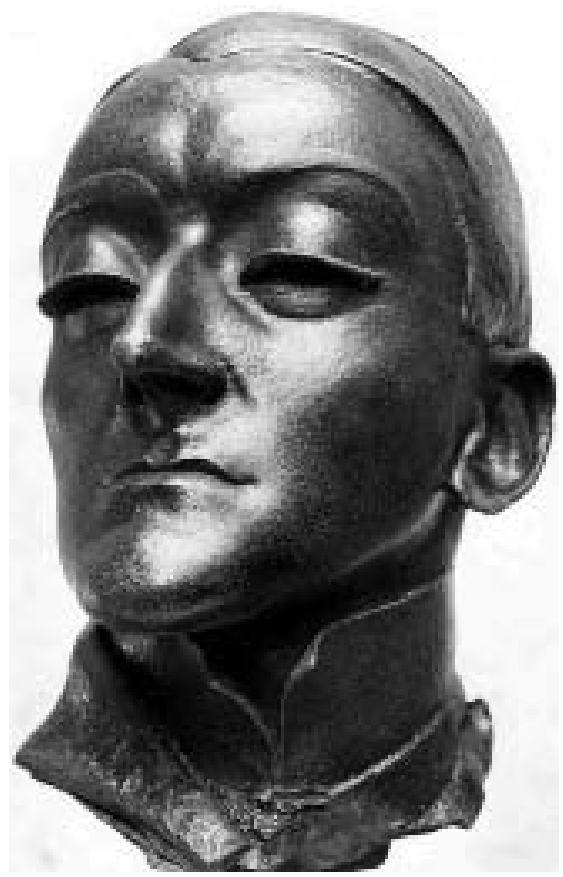

Fig. 8. Ángel Fernandez Soto (4) (1920), foto Pablo Gargallo.

Arch. esp. arte, LXXXIV, 333, ENERO-MARZO 2011, 59-90, ISSN: 0004-0428 


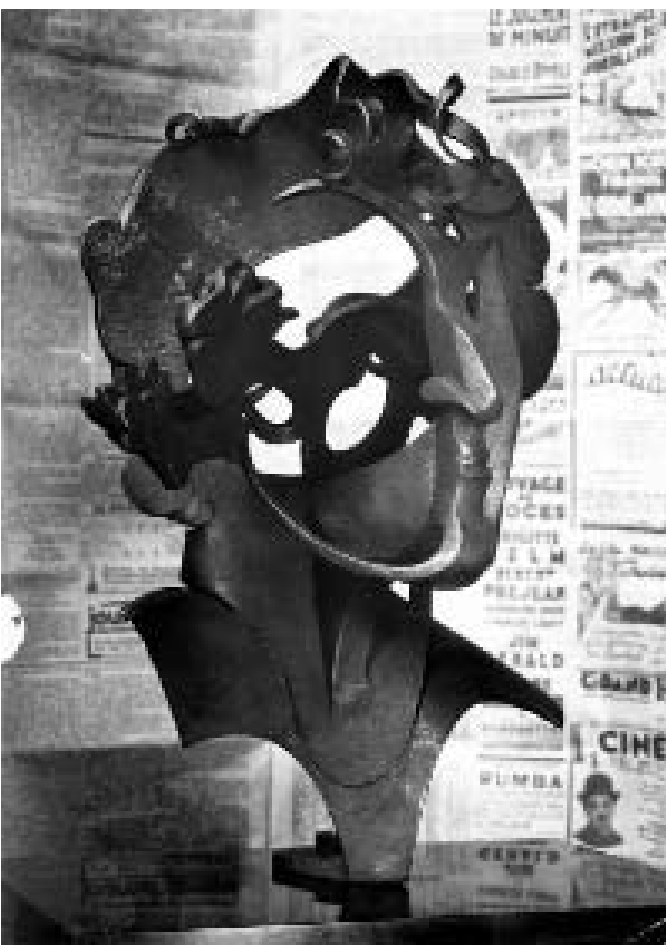

Fig. 9. Homenaje a Chagall (1) (1933), foto Pablo Gargallo.

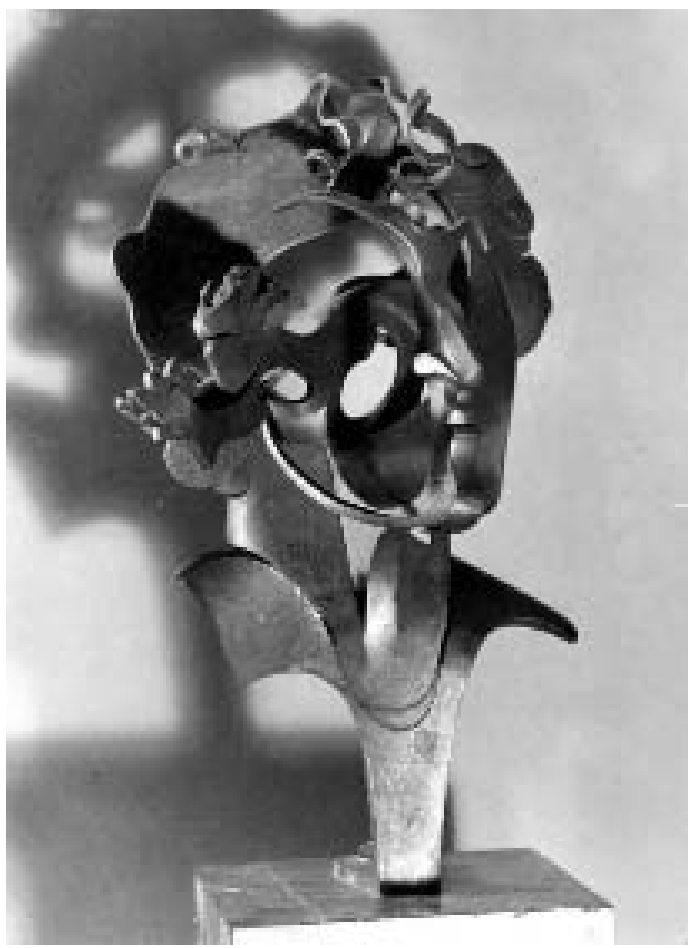

Fig. 10. Homenaje a Chagall (2) (1933), foto Pablo Gargallo.

16 de su revista Nord-Sud, en 1918, donde lleva a cabo una convincente defensa del cine americano. Reverdy señala dos de los aspectos fundamentales que, desde un punto de vista formal, incorpora el cine al bagaje expresivo del arte del siglo XX: el montaje y el primer plano como recursos fundamentales del lenguaje cinematográfico, y que van a encontrar su interpretación formal en el conjunto de manifestaciones artísticas de la época, literatura, pintura, fotografía y también en la escultura.

Pablo Gargallo mostró hacia el cine igualmente un interés personal y profesiona ${ }^{18}$. Además de obras como Pequeña star de 1927, de la que ya existía una versión como joya en plata realizada en torno a 1924, realizó, entre 1930 y 1931, tres versiones distintas de la cabeza de una de las actrices más emblemáticas de la época: Greta Garbo con mechón, Greta Garbo con pestañas y Greta Garbo con sombrero. La serie de retratos escultóricos de Greta Garbo coincide con el debut de la actriz en el cine sonoro y el lanzamiento de su película Anna Christi en versión inglesa y alemana, y en donde sus primeras palabras en pantalla irrumpieron con popularidad, repetidas durante mucho tiempo: "Dame un whisky con ginger ale y no seas pegajoso". Gargallo no conoció personalmente a Garbo. Realizó sus retratos de memoria, o mejor habría que decir basándose en las fotografías que de la actriz circulaban en la época. Con toda probabilidad, y teniendo en cuenta la estilización de las formas, el uso de la luz que la fotógrafo Clarence Sinclair Bull utiliza en sus ampliamente difundidos trabajos de estudio para la Metro-Goldwyn-Mayer desde 1929

18 Ver EDWARD, Lucie-Smith: “Gargallo: máscaras, cine y danza”, en Gargallo, Fundanció Caixa Cataluyna, 2006, pp. 49-55. 
hasta 1941, las poses y la resolución final de retratos como el realizado para la película El beso de 1929, nos inclinan a pensar en la proximidad formal de las tres versiones de la obra de Gargallo y los retratos que Clarence Sinclair Bull hizo para la promoción de las películas de la Metro, encargado de dotar al rostro de Greta Garbo de la iconografía mediante la cual hoy identificamos a la actriz y que Pablo Gargallo resolvió magistralmente en términos escultóricos: los cabellos recogidos que despejan la cara de la actriz o son cubiertos por sombreros y gorras con el objeto de dar protagonismo a las facciones del rostro, sus interminables pestañas (fig. 12).

Las tres esculturas están realizadas a partir de plantillas de cartón, y confirman en la trayectoria de Gargallo el hallazgo del vacío como elemento constitutivo del volumen, la intervención de la mirada del espectador y el montaje y definitiva resolución mediante planos que se entrecruzan y complementan, emparentándose de este modo, desde un punto de vista metodológico, en tanto que procedimiento expresivo, con recursos estrechamente vinculados a modos de ver y hacer cinematográficos. Gargallo era muy

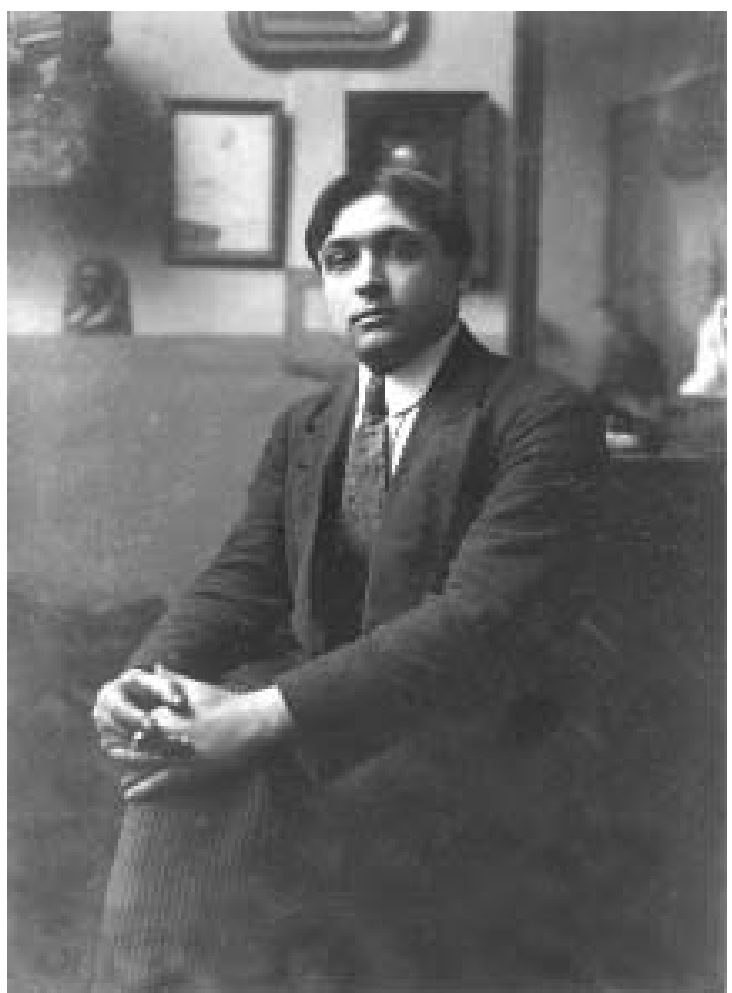

Fig. 11. Pierre Reverdy en el estudio de Gargallo hacia 1913, foto Pablo Gargallo. aficionado al cine, y también al circo, a donde acudía en compañía de amigos entre los que se encuentran de forma asidua el escultor Manolo, el ceramista Llorens Artigas o el actor Gaston Modot $^{19}$. Estos dos últimos actuaron por aquellos años en la hoy famosa película de Luis Buñuel L'Age d'or. Gaston Modot como protagonista, de amante de Lya Lys, la hija de la marquesa, y Llorens Artigas, que se encuentra con Buñuel en un bar de la Cité porque no ha podido entrar a la proyección de El acorazado Potemkin y la conferencia que Eisenstein imparte en la Sorbona, y es invitado a participar en la película, en donde actúa de gobernador con la cabeza rapada y un gran bigote. Gargallo y Buñuel se conocían pero nunca los unió una relación de amistad. La diferencia de edad y el carácter serio de Gargallo no sintonizaba con las veleidades, el humor y los juegos que caracterizaban el espíritu y hasta cierta frivolidad del surrealismo.

A propósito de la familiaridad de Gargallo con el mundo del cine, su hermano menor, Francisco, fue director y obtuvo gran reconocimiento en España por aquellos años. Sabemos que rodó películas como La última cita (1928), Sor Angélica (1934), con gran éxito de público llegando a permanecer en cartel durante meses en Madrid y Barcelona, Eran tres hermanas (1940), la única que se conserva y permanece en Filmoteca Española a la espera de su restauración, y El sobre lacrado (1941). El artista famoso que por aquel entonces gozaba de éxito económico con películas de amplia repercusión popular no era Pablo sino su hermano Francisco Gargallo, por aquel entonces director de películas.

19 Consultar Permanyer, Lluís: Los años difíciles, Barcelona, Lumen, 1975. 


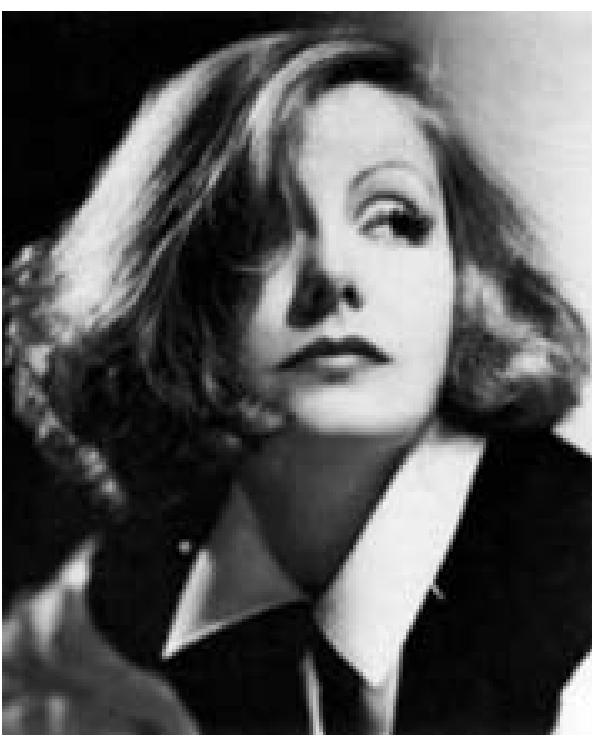

Fig. 12. Greta Garbo (1929), foto Clarence Sinclair Bull.

Entre 1924 y 1925 Pablo Gargallo empieza a trabajar con plantillas en obras como Pequeña bailarina, Pequeña máscara de Arlequín o Pequeña Star. El uso de estas plantillas de cartón que, a modo de patrones, permite al escultor conservar un modelo a partir del cual realizar versiones de una misma obra, implica consecuencias que van más allá de una justificación exclusivamente utilitaria. Cada una de las piezas recortadas viene a constituir la escultura final una vez "montadas" del mismo modo que se montan los planos en una secuencia cinematográfica. Sólo la unión de cada uno de los fragmentos que constituyen la secuencia permite un ensamblaje visual que llena la elipsis, los vacíos, los silencios, que existen entre cada una de las tomas. El cine da protagonismo indiscutible al público que, con su participación activa, da sentido y completa la articulación narrativa del film. Tanto es así que al principio, cuando el espectador carecía de la competencia necesaria para leer imágenes, los cines disponían de un explicador que suministraba las claves argumentales para seguir la película. No deja de sorprendernos la forma en que Gargallo describe el funcionamiento de la escultura recurriendo a términos como "serie de imágenes incompletas" y simultáneas en donde, para entender y completar la composición, el ojo se desplaza. "La escultura -escribe Gargallo- es una serie de imágenes incompletas casi simultáneas de una composición. Para apreciar adecuadamente las diferentes partes de esta composición, el ojo se ve forzado a desplazarse" ${ }^{20}$. Resulta más que obvia la similitud entre el modo de entender el funcionamiento perceptivo de la escultura y los procedimientos visuales incorporados por la simultaneidad de la imagen cinematográfica (figs. 13 y 14).

El encuadre, como rasgo formal clave del discurso visual, tanto fotográfico como cinematográfico, encuentra su eco en las reflexiones del escultor cuando afirma que "la composición escultórica tiene sus puntos de vista perfectamente definidos por la importancia plástica de sus diferentes partes" 21 . La escultura para Gargallo es el resultado de una serie de elementos asociados. La unión de esos puntos de vista parciales trae como resultado una composición dinámica y abstracta del espacio, al igual que sucede en la reconstrucción intelectual mediante planos cinematográficos. De hecho, Gargallo utiliza también este término al referirse al modo en que cada una de las partes de una escultura se asocia mediante "planos" con el objeto de componer su propio volumen. "Cada parte de la composición escultórica -escribe- tiene su volumen con sus planos, sus diferentes superficies y dimensiones" 22 . Junto al montaje de tomas y superficies, la importancia de los detalles cobra con el primer plano un valor indiscutible para el arte que nace y se desarrolla con el cine. La passion de Jeanne d'Arc de Carl Theordor Dreyer, donde primerísimos planos cobran una importancia espectacular, es de 1928, el mismo año en que se funde Kiki de Montparnasse. Se trata de una escultura resuelta mediante la síntesis de unos pocos detalles significantes: el corte de pelo a lo garçon, el perfil de la nariz con el lóbulo derecho, el ojo derecho y media boca al lado contrario. Esta manera de recurrir a fragmentos del rostro

\footnotetext{
${ }^{20}$ Gargallo, Paris, éditions Carmen Martínez, 1979,

${ }^{21}$ Ibid., p. 83.

22 Ibid., p. 98.
} 


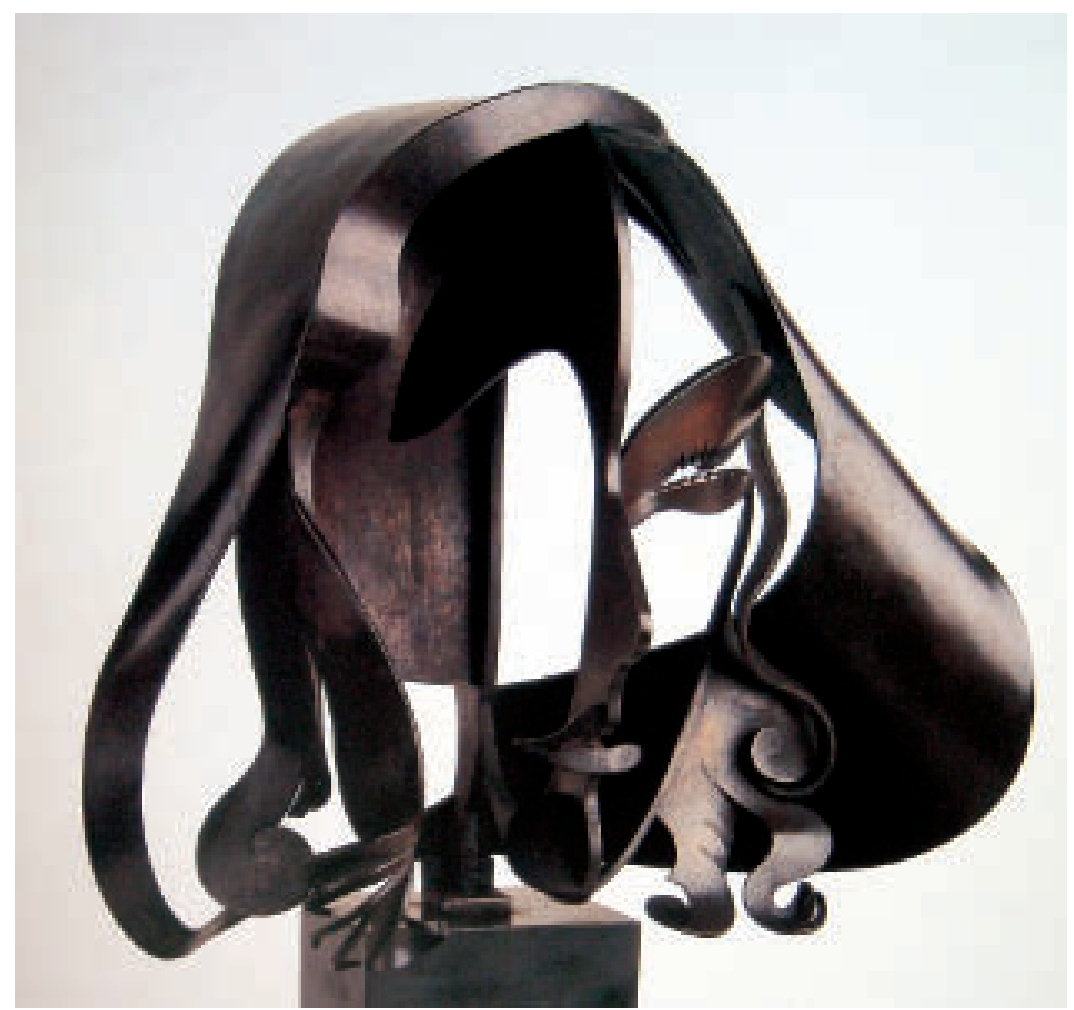

Fig. 13. Greta Garbo con sombrero (1931), foto Emmanuel Sougez.

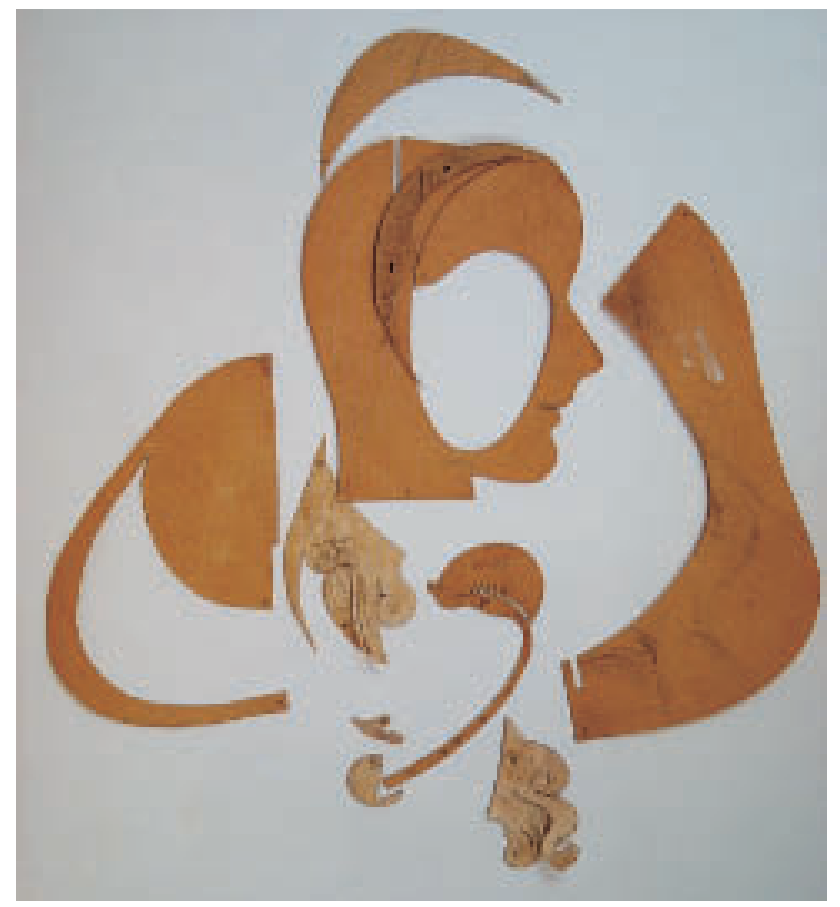

Fig. 14. Greta Garbo con sombrero, 10 cartones recortados (1931).

Arch. esp. arte, LXXXIV, 333, ENERO-MARZO 2011, 59-90, ISSN: 0004-0428 
para alcanzar una imagen sintética se desarrolla y alcanza su máxima expresión en los retratos de Greta Garbo.

No cabe duda de que la literatura, la fotografía y el cine desempeñaron un papel más que anecdótico en el desarrollo personal, intelectual y artístico de Pablo Gargallo. Sus amigos parisinos fueron una fuente de estímulo e intercambio que se ve reflejada en su trabajo como escultor. Su amistad con el poeta Pierre Reverdy significó una puesta en contacto con las ideas del cubismo que encuentran su eco y se plasman en soluciones formales en uno de los caminos más importantes abiertos por Gargallo. La fotografía, mucho más que como fuente documental o herramienta utilitaria, ofrece al escultor la posibilidad de contemplar los volúmenes en términos de luces y sombras, y no es casual que en manos de fotógrafos profesionales, como Sougez o Bescón, sus esculturas cobren una dimensión decididamente justa e impactante. Y en lo que respecta al séptimo arte, Gargallo fue testigo y partícipe de su tiempo, homenajeando al cine y sus estrellas demostrando al mismo tiempo un fino sentido del humor. La permeabilidad de la escultura con tres manifestaciones artísticas concomitantes reflejan la permeabilidad de un artista atento al acontecer de su tiempo, inmerso y transformándolo en tanto que protagonista activo, sentando las bases del arte moderno para el siglo XX.

ANTONIO ANSÓN Universidad de Zaragoza 